
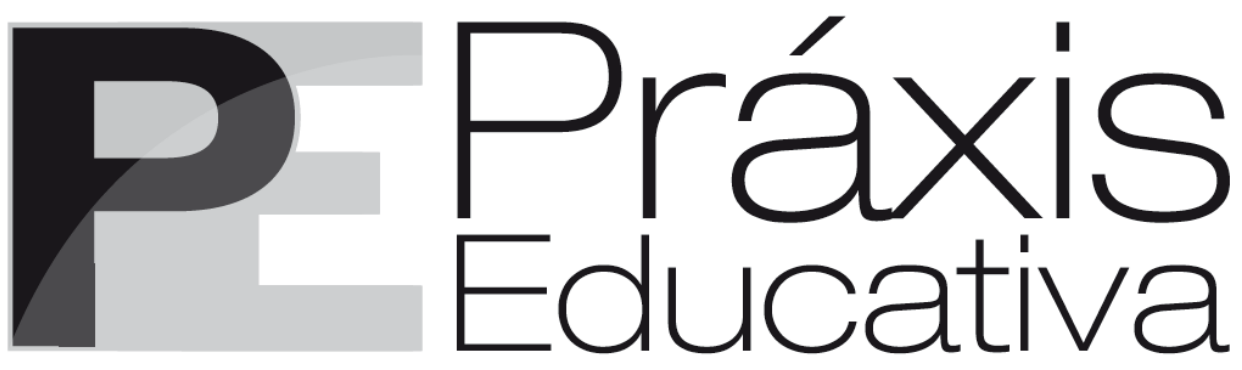

ISSN 1809-4031

elSSN 1809-4309

https://doi.org/10.5212/PraxEduc.v.16.16810.014

\title{
A supervisão pedagógica e a formação contínua: mitos e percepções por meio de narrativas dos professores do Distrito de Monapo
}

\section{Pedagogical supervision and continuous training: myths and perceptions through narratives of teachers from Monapo District}

\section{La supervisión pedagógica y la capacitación continua: mitos y percepciones por medio de las narrativas de los docentes del Distrito de Monapo}

\author{
Wilson Profírio Nicaquela* \\ https://orcid.org/0000-0001-6810-0655 \\ Adelino Inácio Assane ${ }^{* *}$ \\ iD https:/ / orcid.org/0000-0001-7592-2817
}

\begin{abstract}
Resumo: Que percepções os professores têm sobre a supervisão pedagógica? Esta pode ser a questão fundante de uma pesquisa narrativa com os professores do distrito de Monapo, na Província de Nampula, Norte de Moçambique, que desenvolvemos no âmbito do curso de Doutoramento em Inovação Educativa, na Faculdade de Educação e Comunicação da Universidade Católica de Moçambique. O objectivo foi analisar as experiências dos professores sobre a supervisão pedagógica. Para tal, pedimos aos professores para que produzissem textos, narrando suas vivências na escola, enquanto objectos e/ou sujeitos do processo de supervisão. Esse exercício consideramos como metodologia do nosso estudo. Para a efectivação do objectivo, tomamos como indicadores: o papel do supervisor, as competências do supervisor, a percepção do que é a supervisão e os desafios da supervisão. Por meio dos depoimentos dos professores, pudemos concluir que há uma evidência no âmbito das implicações para o supervisionando, pois os procedimentos tidos na sua execução, na sua percepção, não são os mais adequados para o acompanhamento e o desenvolvimento do trabalho docente, uma vez que entendem a supervisão como uma prática administrativa, com função fiscalizadora e punitiva. Desse modo, eles não consideram um
\end{abstract}

\footnotetext{
* Doutorando em Inovação Educativa pela Universidade Católica de Moçambique; Mestre em Educação em Ciências de Saúde pela Universidade Lúrio; Licenciado em Psicologia Escolar pela Universidade Pedagógica de Moçambique; Grupo de Estudos e Pesquisas em Educação Popular e Cotidiano Escolar \& Associação Moçambicana de Estudos Aplicados (AMEA); Docente da Faculdade de Ciências Sociais e Humanas da Universidade Lúrio, Ilha de Moçambique. E-mail: <wilsonnicaquela@gmail.com>.

** Doutorado em Educação pela Universidade Federal Fluminense - Brasil; Licenciado em Pedagogia e Psicologia e Mestre em Educação - Formação de Formadores pela Universidade Pedagógica de Moçambique. Docente da Universidade Rovuma - Nampula. Coordenador do Grupo de Estudos e Pesquisas em Educação Popular e Cotidiano Escolar (GEPECE) \& Associação Moçambicana de Estudos Aplicados (AMEA); Consultor Pedagógico da Empresa de Consultoria Paidéia \& Humanitas, Lda. E-mail: <adiassane@yahoo.com.br>.
} 
A supervisão pedagógica e a formação contínua: mitos e percepções por meio de narrativas...

instrumento auxiliar do seu desenvolvimento profissional. Assim, quando a supervisão toma o carácter de assistência à aula, esse processo tem sido considerado um "acontecimento" e não uma prática espaço/momento de formação para alguns supervisores e/ou professores.

Palavras-chave: Desenvolvimento profissional. Experiência em supervisão pedagógica.

Abstract: What perceptions do teachers have about pedagogical supervision? This may be the founding question of a narrative research with teachers of Monapo district, in Nampula Province, Northern of Mozambique, which we developed within the scope of the $\mathrm{PhD}$ course in Educational Innovation, at the Faculty of Education and Communication of the Catholic University of Mozambique. The objective was to analyze teachers' experiences on pedagogical supervision. For this, we asked teachers to produce texts narrating their experiences at school, as objects and/or subjects of the supervision process. This exercise is considered as the methodology of our study. To achieve the objective, we took as indicators: the role of the supervisor, the skills of the supervisor, and the perception of what supervision is and the challenges of supervision. Through the testimonies of the teachers, we could conclude that there is evidence at the level of the implications for the supervisee, because the procedures employed, in their perception, are not the most suitable for the monitoring and development of the teaching work, since they understand supervision as an administrative practice, with a supervisory and punitive function. Hence, they do not consider it as an auxiliary instrument for their professional development. Thus, when the supervision takes the character of assistance to the class, this process has been considered an "event" and not a practical space/training moment for some supervisors and/or teachers.

Keywords: Professional development. Pedagogical supervision experience.

Resumen: ¿Qué percepciones tienen los docentes sobre la supervisión pedagógica?. Esta puede ser la pregunta fundacional de una investigación narrativa con docentes del distrito de Monapo, en la Provincia de Nampula en el Norte de Mozambique, que desarrollamos en el marco del curso de Doctorado en Innovación Educativa, en la Facultad de Educación y Comunicación de la Universidad Católica de Mozambique. El objetivo fue analizar las experiencias de los docentes sobre la supervisión pedagógica. Para ello, solicitamos a los docentes que produzcan textos, narrando sus vivencias en la escuela, como objetos y / o sujetos del proceso de supervisión. Este ejercicio se considera como la metodología de nuestro estudio. Para lograr el objetivo, tomamos como indicadores: el rol del supervisor, las competencias del supervisor, la percepción de lo que es la supervisión y los desafíos de la supervisión. Por medio de los testimonios de los docentes, pudimos concluir que hay una evidencia a nivel de las implicaciones para el supervisado, porque los procedimientos tomados en su ejecución, en su percepción, no son los más adecuados para el seguimiento y desarrollo del trabajo docente, una vez que comprenden la supervisión como práctica administrativa, con función supervisora y punitiva. De ese modo, no lo consideran un instrumento auxiliar para su desarrollo profesional. Así, cuando la supervisión toma el carácter de asistencia a la clase, este proceso ha sido considerado un "evento" y no una práctica espacio / momento de formación para algunos supervisores y / o profesores.

Palabras clave: Desarrollo profesional. Experiencia en supervisión pedagógica.

\section{Introdução}

Com este texto procuramos reflectir criticamente como o trabalho de supervisão deve(ria) constituir um meio para a melhoria das actividades pedagógicas no meio escolar. Importa salientarmos que, neste trabalho, fazemos triangulações entre nossas experiências profissionais, acepções teóricas e os resultados do trabalho de campo.

Com o aumento (des)acelerado da rede escolar em Moçambique e a crescente procura das instituições de ensino, acaba tornando as condições de ensino-aprendizagem menos eficientes. Associado a esse cenário, de acordo com Pe. Sapato (2016), encontra-se a função utilitarista da escola, cuja procura de certificados guia os interesses das pessoas pela frequência de vários cursos, sobretudo superiores ligados ao ensino. A competência dos professores sujeita-se ao questionamento a partir da insatisfação de algumas necessidades do mercado de emprego. Assim,

Práxis Educativa, Ponta Grossa, v. 16, e2116810, p. 1-17, 2021

Disponível em: < https://www.revistas2.uepg.br/index.php/praxiseducativa> 
este texto faz um percurso sobre a competência profissional, os desafios da educação, a supervisão na generalidade, para além do seu historial em Moçambique, associado à dinâmica da escola formal com o fim de demonstrar a sua vitalidade no processo de formação contínua do professor.

\section{O fluxo conceptual da competência}

A noção de competência está repleta de várias subjectividades. A partir desse conceito, podemos responder a vários significados em torno de aptidões, hábitos, habilidades e atitudes. Hoje, fala-se de competências interculturais, competências linguísticas, competências sociais, competências de aprendizagem, competências técnicas ou tecnológicas, sem esquecer as chamadas competências profissionais (que constitui o foco desta reflexão). Genericamente, consideramos um indivíduo competente a partir de suas características singulares, especialmente o conjunto de habilidades, que desenvolve de acordo com a sua profissão: arquitecto, enfermeiro, mecânico auto, electricista, pescador, professor e afins (BARBOSA, 1999 apud BARBOSA et al., 2016). As competências não constituem um dado inato; assim, a competência é um exercício que se efectiva a partir do envolvimento activo do próprio sujeito que se anseia tornar competente.

Na óptica de Barbosa et al. (2016), a competência tem a ver com a habilidade, um conceito que se restringe ao saber fazer. Com efeito, a identificação de fenómenos, a resolução de problemas profissionais, o julgamento de factos, a capacidade de análise ou a produção de sínteses tem a ver com a questão de competências. Assim, a competência pode ser desenvolvida a partir de uma aprendizagem formal (na escola ou curso de formação específica) ou por meios informais (aprendizagem ao longo da vida, por imitação consciente). Entretanto, na realidade moçambicana, é muito controverso determinar indicadores de qualidade ou de avaliação da competência dos profissionais formais, cujo exercício da actividade requerem uma formação especializada. Esse cepticismo baseia-se nas conclusões em volta do debate sobre a contradição entre o acesso ao emprego por afinidades e o acesso ao emprego devido ao mérito.

O Professor Miguel Lopes, um antigo quadro Sénior do Ministério de Educação nos anos a seguir da Independência ${ }^{1}$, falando no $1^{\circ}$ Encontro Nacional de Pesquisas em Educação na Universidade Eduardo Mondlane (2017), argumentava que agora é suspeito na educação, ou em instituições públicas, falar de méritos profissionais ou académicos, pois há entradas por quotas. Dessa forma, os apelidos e as origens familiares determinam a proeminência e a comparação é feita em relação àqueles que nunca tiveram oportunidade (LOPES, 2017). Portanto, há sujeitos que abraçam determinadas profissões sem que necessariamente tenham o mínimo das habilidades para essa profissão. A escola ou a formação profissional parecem não ser espaços que ajudam a aquisição de subsídios elementares para o desenvolvimento de habilidades profissionais. Os certificados são usados como simples credenciais. Subentendemos que os certificados e os diplomas na actualidade não passam de passaportes, pois nem todos os que dispõem deles são necessariamente viajantes.

De algum tempo para a actualidade, a escola deixou de ser uma necessidade com a qual se conquista conhecimentos, passou a ser um meio para ganhar dinheiro (NACUO, 2008). Por conseguinte, um trabalho que era realizado antes com sucesso por um profissional de nível médio, básico ou elementar, hoje é realizado por licenciados, mestres, que são insuficientes quando o executam. Portanto, isso pode conduzir-nos a um entendimento comum, que tais profissionais não dispõem de competências técnicas (habilidades) para o exercício das suas profissões.

Devido a essa realidade, as universidades vivem, metaforicamente, a época antecedente das guerras mundiais. Enquanto as potências mundiais na época eram tomadas pela fobia da invasão

125 de junho de 1975.

Práxis Educativa, Ponta Grossa, v. 16, e2116810, p. 1-17, 2021

Disponível em: < https://www.revistas2.uepg.br/index.php/praxiseducativa> 
A supervisão pedagógica e a formação contínua: mitos e percepções por meio de narrativas...

externa e corriam aos armamentos, a nossa geração, ameaçada pelo magro salário ou pela pobreza, corre para os certificados/diplomas. Não importa onde? O quê? Como? E, para que nos formamos? Não estamos interessados pelas competências profissionais. Há tantos professores que trabalham para salário, mais do que pela profissão.

Gostaríamos de chamar atenção a não exclusividade deste fenómeno para Moçambique, pois trata-se de uma situação que se regista noutros contextos. Nascimento (2011) aborda a luta pelos certificados no Brasil e aponta a Administração Pública como incubadora. Em Moçambique, a exigência do certificado pelo Tribunal Administrativo como indicador na mudança, na conversão de carreira profissional e, consequentemente, o aumento salarial, continua sendo agente motivacional na procura de um diploma.

Segundo Borges (2004), aqueles que não conseguem acompanhar a corrida pelos diplomas são progressivamente substituídos pelos que conquistaram credenciais do sistema educacional, mesmo que essas credenciais e os conhecimentos não sejam necessariamente indispensáveis pelo bom desempenho (competências). Com efeito, no lugar de resolver o problema salarial ou de acesso ao emprego condigno, emergem novos problemas: aumento de indivíduos formados com (in)competências requeridas e/ou desempregados.

Como fazemos referência desde o princípio, a noção de competência incorpora a componente prática, para tal tem-se em conta não só os aspectos cognitivos, como também as habilidades psicomotoras e afectivas. A competência embora possa ser tratada na perspectiva da colectividade, a sua abordagem foca-se nas capacidades individuais. Assim, o centro de atenção é o sujeito e não suas atribuições ou funções (NEVES, 2015 apud BARBOSA et al., 2016).

\section{Competências profissionais do professor}

Deliberadamente iniciamos a discutir questões voltadas para a competência do professor antes de mergulhar no tema destacado (supervisão). Essa escolha é influenciada pelo facto da acção coordenada do supervisor pedagógico recair sobre o trabalho docente, visto que a avaliação das competências técnicas e profissionais do professor é uma das atribuições da supervisão escolar.

Barbosa et al. (2016) são de opinião que a profissão de professor não se distancia de tantas outras, é uma prática que durante o seu exercício exige certos domínios. Em qualquer subsistema de ensino (primário, secundário, superior, técnico-profissional ou vocacional), as competências do professor são estruturadas em disciplinas específicas, requerendo ao seu fazedor o domínio não só do que ensinar, mas, essencialmente, como ensinar, quando ensinar e a quem ensinar.

Com as respostas ou as satisfações dessas inquietações, o professor de qualquer subsistema de ensino ou nível de escolaridade estará a revelar as competências técnicas e profissionais requeridas pela actividade que desenvolve. Perrenoud e Thurler (2008) estabelecem algumas competências técnicas que devem ser demostradas pelo professor no exercício de suas funções, mormente:

- Organizador e dirigente das situações de aprendizagem.

- Administrador do gradualismo de ensino e das aprendizagens.

- Gerador e percursor dos dispositivos de diferenciação.

- Envolvente e inclusivo para com os alunos em suas aprendizagens e trabalhos.

- Hábil para trabalhar em equipa.

- Participante activo na administração da escola.

Práxis Educativa, Ponta Grossa, v. 16, e2116810, p. 1-17, 2021

Disponível em: < https://www.revistas2.uepg.br/index.php/praxiseducativa> 
- Informador e envolvente dos pais.

- Utilizador das novas tecnologias.

- Cumpridor de deveres e obediente aos dilemas éticos da profissão.

- Ávido do saber e administrador da sua própria formação contínua.

Nesse sentido, um professor competente é o que consegue ser autossuficiente na resposta das diferentes situações que a prática pedagógica lhe impõe. Um equilíbrio emocional, domínio de suas atribuições, a sociabilidade e espírito de cooperação tornam o professor profissional mais hábil e cada vez mais hilariante para com os colegas de carreira. A explosão irreversível das tecnologias de informação e comunicação fez emergir a chamada sociedade de informação e comunicação ou, simplesmente, sociedade de conhecimento. Isso pode, de um lado, criar ilusões na abordagem das competências profissionais do professor (ao confundir o acesso à informação com o conhecimento ou sabedoria); e, por outro, desfia o professor a ser mais ousado para que seu papel continue intacto no processo de ensino-aprendizagem.

Assim, torna-se necessário desenvolver novas competências associadas à flexibilidade na adaptação, ao domínio dos conteúdos, ou à autoconfiança, mas, conforme referimos anteriormente, exige-se outras condições, tais como: a comunicação, o trabalho em equipe, o nível de sociabilidade, entre outras (LARROSA, 2014; TAVARES, 2000). Essa nova série de competências técnicas exigidas ao professor permitem a formação de pessoas integras, capazes de se adaptarem a novas situações, ao mesmo tempo que se sujeitam às mudanças que as dinâmicas sociais vão lhes impondo (TAVARES, 2000).

Segundo Libardi (2010, p. 10), “[...] nos dias de hoje, torna-se necessário rever os paradigmas educacionais para oferecer um aprendizado voltado ao pensar, analisar, criticar, e não repetir o que foi dito". O processo de ensino-aprendizagem é tão dinâmico que intima aos professores uma flexibilidade para responder às carências do momento. A figura do professor contínua imprescindível, mesmo que haja crenças sobre a possível substituição dele com os avanços das tecnologias de informação e comunicação. O professor é convidado a antecipar os eventos.

Perrenoud e Thurler (2008) são de opinião que, na construção do conhecimento, o professor competente não faz por improviso, passa, necessariamente, pela planificação; além disso, ele devia pensar em uma possível pedagogia construtivista; garantir o sentido dos saberes, a criação de situações de aprendizagem, a administração de uma dissemelhança regulação de percursos e processos, entre outros. O desenvolvimento e a efectivação desses processos constituem objecto de trabalho dos supervisores e/ou inspectores (assunto a abordar mais adiante).

Segundo Sacristán (2000, p. 166), “[...] a actividade dos professores é uma acção que transcorre dentro de uma instituição. Por essa razão, a sua prática está inevitavelmente condicionada. A acção observável é fruto da modelação que os professores realizam dentro de campos institucionais de referência". O autor argumenta que, para o professor ser competente, ele não precisa tomar decisões das suas acções no vazio, mas no contexto da realidade do seu local de trabalho, em uma instituição que tem suas normas de funcionamento marcadas, às vezes, pela administração, pela política curricular, pelos órgãos do governo, de uma escola ou pela simples tradição que se aceita sem discutir. Em suma, o professor não selecciona as condições nas quais realiza seu trabalho e, nessa medida, sequer pode escolher, muitas vezes, como desenvolvê-lo.

Com efeito, há necessidade de se entender o professor como um profissional activo a que se responsabiliza a tarefa de traduzir o currículo, a partir de experiências práticas na definição dos conteúdos para determinados alunos, na selecção dos meios mais adequados para eles, sempre observando exclusivamente a realidade (LIBÂNEO, 1994). O professor não pode se comparar a 
A supervisão pedagógica e a formação contínua: mitos e percepções por meio de narrativas...

outras profissões liberais de forma linear ou acriticamente. Não é um profissional que possa dispor de uma bagagem de técnicas instrumentais, rotineiras e apoiadas em pretensos conhecimentos científicos fixos e inquestionáveis, à imagem e semelhança de um técnico de frios. O professor é um sujeito que se constrói e constrói os outros na cooperação no tempo e com o tempo.

A universidade, enquanto unidade social, permite a geração de programas colectivos e consensuais por meio da cooperação dos seus actores (alunos, professores e o corpo técnico administrativo), que superam o encolhido limite de uma sala de aula. Nesse sentido, o docente universitário defronta-se com um contexto mais dilatado de condições de partida, que suplantam o individualismo para que se centre em um nível intermédio do pluralismo em que as singularidades são reconhecidas. Isso supõe complexas vantagens na ponderação e prossecução do processo formativo do professor.

\section{Dos desafios da educação ao processo de supervisão em Moçambique}

A educação tal como outros indicadores de desenvolvimento humano, mormente a saúde, o meio ambiente, o saneamento básico e afins, enfrenta uma série de desafios de natureza conjuntural e estrutural. Conforme consta na Lei $\mathrm{N}^{\circ}$ 18/2018 de 28 de dezembro (REPÚBLICA DE MOÇAMBIQUE, 2018) a nova Lei do Sistema Nacional de Educação (SNE²), a educação é um dos princípios gerais e direito constitucionalmente estabelecido. Assim, o esforço de satisfazer esse direito torna-se o primeiro desafio da educação em Moçambique.

Tal direito tem sido condicionado por vários factores, nomeadamente: a falta de condições financeiras por parte das famílias para suportar os custos de matrículas, material e uniforme escolar, carência de escolas, insuficiência de professores, insuficiência e/ou precariedade das infraestruturas. O Inquérito Demográfico de Saúde, realizado conjuntamente ao Instituto Nacional de Estatística e ao Ministério da Saúde (2011), ponta a explosão demográfica que o país vivencia, que, desde o fim da guerra dos 16 anos $^{3}$, tem sido um factor saliente e embaraçador na efectivação dos planos educacionais. Portanto, como consequência, o número de crianças que procuram a escola tem sido muito superior, fazendo com que haja limitações de ingresso.

A transição de uma economia fechada e centralizada para uma economia do mercado e a aderência de Moçambique aos diversos organismos internacionais, tais como: o Banco Mundial, o Fundo Monetário Internacional, a Organização das Nações Unidas para a Educação, a Ciência e a Cultura (UNESCO), o Programa das Nações Unidas (PNUD) para o Desenvolvimento (esta última instituição que avalia o nível de execução dos, então, Objectivos de Desenvolvimento do Milénio, agora denominados Objectivos de Desenvolvimento Sustentável), o aparecimento de novos actores políticos e educacionais (instituições privadas) com a Constituição de 1990 (que prima pelo pluralismo político e exercício da democracia), desencadeou uma série de mudanças no Sistema Nacional de Educação que culminou com a aprovação da Lei No 6/92 do SNE.

O Comité de Conselheiros da Agenda 2025 fundamentou na necessidade de encontrar novas estratégias para prover a educação a mais cidadãos moçambicanos, pois, no seu entender:

Apesar do aumento tanto da rede escolar como do número de crianças que frequentam
as escolas, a oferta dos serviços educacionais ainda não é abrangente pelo que nem
sempre oferece muitas oportunidades de progressão para outros níveis de ensino. Os
alunos que passam do EP1 para o EP2 não podem continuar com os seus estudos por
falta de escolas para esse nível, próximas dos seus locais de residência. Igualmente, há

\footnotetext{
${ }^{2}$ Houve outras leis antes desta, nomeadamente: Lei № 4/83 de 23 de março; Lei № 6/92, de 24 de maio.
}

${ }^{3}$ Guerra Civil que durou entre 1977 e 1992.

Práxis Educativa, Ponta Grossa, v. 16, e2116810, p. 1-17, 2021

Disponível em: < https://www.revistas2.uepg.br/index.php/praxiseducativa> 
carência de escolas técnico-profissionais a todos os níveis, sobretudo nas zonas rurais. Os recursos adicionais são escassos; há uma grande desigualdade de acesso entre o campo e a cidade e mesmo entre as regiões Norte, Centro e Sul [de Moçambique]. (COMITÉ DE CONSELHEIROS, 2003, p. 147).

Olhando pelas barreiras que o país enfrenta na provisão de uma educação de qualidade e a satisfação das necessidades de acesso às escolas da rede pública nacional pelas crianças carenciadas e, sobretudo, das zonas rurais que constitui a maioria da população estudantil dos ensinos primário e secundário, houve necessidade de definir estratégias sectoriais. Assim, na educação, iniciou-se o desenho de vários planos estratégicos desde o ensino primário, passando pela Alfabetização e Educação de Adultos, o Ensino Secundário, o Ensino Técnico-Profissional, Formação de professores e Ensino Superior. Tudo isso foi fruto da operacionalização de vários planos com destaque para a Agenda 2025.

Entretanto, a ausência de linha orientadora dos Ministérios ${ }^{4}$, que tutelem os vários subsistemas de educação, assim como politização excessiva do ensino, fez com que, desde 2016, fosse abandonada a política de elaboração de planos estratégicos de cada subsistema. Isso porque, em Moçambique, sempre que se indica um novo Ministro de Educação e/ou de Ensino Superior acontecem mudanças estruturantes e espontâneas. Esse fenómeno acontece mesmo que o Ministro seja indicado no final do mandato legislativo.

Embora haja esforço de massificar a educação, a dificuldade que se enfrenta é o desnível entre os projectos educacionais e o tipo de alunos graduados em tais projectos (ensino primário, ensino secundário ou primário). Pe. Sapato (2016) refere que, no nosso país, há mais procura de diplomas para assegurar emprego ou melhoria de salário e não competências, ou habilidades técnicas e profissionais, que testemunham o indivíduo ter conquistado um conhecimento de forma sistemática.

A partir dos enormes desafios que o sistema educacional em Moçambique enfrenta, podese perceber que a supervisão enquanto componente desse sistema trilha pelas mesmas sinuosidades. Desse modo, enquanto não haver condições para o funcionamento regular das instituições de ensino, de formação ou de gestão, sempre haverá excessos e deslizes e mitos na excussão e nas percepções em volta da supervisão pedagógica.

Medeiros, Fortunado e Araújo (2020), em um artigo publicado na Revista Práxis Educativa, cuja discussão são os estágios orientados e supervisionados no Brasil, fazem referência às difíceis condições de efectivação do trabalho de supervisão de estágio como uma componente formativa de professores do ensino básico. Os autores citam que:

Haja vista condições amiúde difíceis das escolas de Educação Básica para a efetivação
dos estágios como uma experiência coletiva, assim como pelas dificuldades existentes
para o diálogo entre os estudantes, os professores orientadores e os professores
supervisores das escolas, espaços de desenvolvimento dos estágios. Costumeiramente
menciona-se na literatura educacional brasileira a necessidade de uma maior articulação
entre as universidades e as escolas; os estudantes, os professores orientadores e os
professores supervisores das escolas de Educação Básica. (MEDEIROS;
FORTUNADO; ARAÚJO, 2020, p. 30).

No contexto moçambicano, essa falta de diálogo e dificuldades na supervisão enquanto um espaço e momento de formação contínua de professores trascende o nível das instituições vocacionadas na formação de professores e repete-se em nível da tutela do Sistema Nacional de

\footnotetext{
${ }^{4}$ Ministério de Educação e Desenvolvimento Humano e Ministério da Ciência, Tecnologia Ensino Superior e Técnico Profissional.
} 
A supervisão pedagógica e a formação contínua: mitos e percepções por meio de narrativas...

Educação, nomeadamente os Serviços Distritais de Educação Juventude e Tecnologia, as Direcções Provinciais de Educação e Desenvolvimento Humano, assim como o Ministério de Educação e Desenvolvimento Humano, que destacam seus técnicos para junto às escolas desenvolverem a actividade de supervisão. Portanto, a efecticvação da supervisão, ao que nos parece, não só em Moçambique como também em outros países, continua uma miragem, a olhar pelas dificultates que os estudos reportam.

\section{A longa marcha do conceito da supervisão pedagógica}

A supervisão não é uma prática recente, ela vem sendo desenvolvida ao longo do processo evolutivo da humanidade. No passado, em muitos países considerados berço da civilização antiga (Índia, Pérsia, China) registraram marcas da supervisão embora fosse de forma "incipiente". Nessa época, a supervisão era entendida como o processo de controlo ou monitoria das escolas. No sentido restrito, a supervisão sistematizada emergiu na antiga Grécia com o aparecimento de pessoas especializadas para monitorar o funcionamento de uma escola; na Roma antiga, quem assumia o papel de supervisor escolar de forma exclusiva eram os indivíduos responsáveis pelo censo populacional (BARBOSA; MAURIDE, 2017).

A história universal refere que, na Idade Média, a escola esteve sob tutela da Igreja Católica Romana. Portanto, era da responsabilidade da Santa Sé supervisionar as instituições de ensino baseando-se nos princípios da fé. O conteúdo de trabalho era verificar a matrícula, o absentismo, a pontualidade e afins - o que se chama de inspecção. Na Idade Moderna, com o domínio do Renascimento, acelerado pela Revolução Francesa, emerge a figura do inspector, com qualificações e competências para vigiar as escolas. A partir dos princípios do Século XX, aperfeiçoa-se a supervisão escolar com finalidade de controlar o trabalho docente. Nessa fase, o enfoque estendese para o âmbito administrativo e passa a ser considerada a inspecção administrativa (BARBOSA; MAURIDE, 2017).

A supervisão começa a ser abordada de forma sistemática e metódica com a inspiração da organização científica do trabalho empresarial de Frederick Taylor (1911). A organização Científica do Trabalho de Taylor partia do pressuposto de que, se pudesse reduzir ao mínimo os movimentos que os operários tinham de realizar para executar uma tarefa, seria muito fácil multiplicar o seu rendimento (CHAMBEL; CURRAL, 1995). Assim, os serviços prestados pelos trabalhadores das indústrias da época deviam ser rigorosamente controlados pelos chefes dos sectores (supervisores).

Olhando para a essência das teorias clássica que constituem a base científica da supervisão pedagógica, percebe-se que postulavam, de um lado, que a racionalização do trabalho nas instituições deve seguir a ordem vertical, ou seja, do topo para a base, isso na perspectiva de Taylor. Entretanto, na teoria de Fayol, por outro lado, foca-se na maior responsabilidade para o controle da produção que deve ser da responsabilidade daqueles que têm o poder de orientar e controlar aos trabalhadores, esses responsáveis [na verdade chefes de departamentos] assumem o papel de supervisores (CHAMBEL; CURRAL,1995).

\section{Emergência da supervisão pedagógica como prática profissional em Moçambique}

Segundo Golias (1993), na história da educação moçambicana, as marcas da supervisão como prática profissional foram registradas a partir do controle das actividades educativas desenvolvidas pela escola formal (na vigência do colonialismo). A evolução do conceito de supervisão em Moçambique, embora mais flexível devido às rápidas transformações da escala planetária, segue o mesmo processo que em outros contextos.

Práxis Educativa, Ponta Grossa, v. 16, e2116810, p. 1-17, 2021

Disponível em: <https://www.revistas2.uepg.br/index.php/praxiseducativa> 
Portanto, houve uma forma de abordar a supervisão pedagógica durante o colonialismo, nas zonas libertadas e no Moçambique independente. Dois anos depois da nacionalização do ensino, em 1978, foi aprovado o diploma ministerial $N^{o}$ 76/1978, de 11 de setembro, que instituiu a Inspecção-Geral da Educação e Cultura, como primeiro órgão formal, competente para levar a cabo as acções de supervisão em nível nacional (REPÚBLICA DE MOÇAMBIQUE, 1978).

Assim, desde as zonas libertadas até a aprovação da segunda Lei do Sistema Nacional de Educação (Lei No 6/92), que actualiza a 1a , a Lei No 4/83 (REPÚBLICA DE MOÇAMBIQUE, 1983), a supervisão ficou confinada à fiscalização da educação e estava associada à tomada de medidas administrativas sobre os funcionários da educação. Foi a partir da Lei N ${ }^{\circ}$ 6/92 que se estabeleceu claramente a distinção entre a inspecção e a supervisão educacional e, posteriormente, reforçada pela Resolução No 1/2011, de 14 de abril, que define estatuto orgânico do Ministério de Educação. Esse instrumento concebe a Inspecção como uma unidade diferente dos técnicos de apoio - supervisores (BARBOSA; MAURIDE, 2017).

A supervisão passou, portanto, a ocupar-se exclusivamente em actividades de apoio às escolas, sobretudo no desempenho profissional dos professores. Enquanto isso, a inspecção ocupa-se na verificação do nível de cumprimento das normas estabelecidas pelas instituições educativas, desde os programas de ensino, a execução dos orçamentos, assim como as tarefas e as orientações obrigatórias da educação.

\section{Percepções actuais sobre o papel da supervisão pedagógica na escola}

Neagley e Evans (1961 apud ALVES, 2013 p. 12) concebem a supervisão pedagógica como sendo "[...] serviço técnico destinado fundamentalmente a estudar e melhorar cooperativamente todos os factores que influem no crescimento e desenvolvimento do educando". O supervisor pedagógico é, portanto, quem realiza essas tarefas. Com as dinâmicas sociais e os progressos científicos, a supervisão pedagógica alcança proporções impreteríveis, tendo-se tornado área exclusiva de especialização de muitos profissionais da educação entre gestores e professores.

Em linhas gerais, há uma tendência de se conceber a supervisão a partir da associação entre fiscalização para normalizar a actividade educacional e o processo formação e actualização contínua das práticas profissionais do professor. Esse movimento envolve vários actores que transcendem o espaço físico da escola. Por conseguinte, por meio da supervisão, são operacionalizados vários processos desde a gestão, avaliação e orientação para acção, tanto do professor assim como do próprio supervisor (GASPAR; SEABRA; NEVES, 2012). Por seu turno, Alves (2013, p. 12) considera a supervisão como " [...] a acção positiva e democrática destinada a melhorar o ensino, mediante a formação contínua de todos os interessados: educando, professor, supervisor, administrador escolar e pais, ou outra pessoa interessada no problema".

Olhando a acepção dos autores supracitados, podemos considerar a supervisão como uma prática que deve ser encarada por todos, realizada com todos, para que os seus efeitos sejam um usufruto de toda a comunidade educativa, pois a tarefa de supervisionar a educação e a escola transcende os parâmetros institucionais. A partir dessa complexidade, Moreira (2000) refere que os supervisores são uma peça fundamental no processo de facilitação do desenvolvimento profissional, especialmente no fortalecimento de actitudes, capacidades, competências tanto de professores em formação, ou em exercício, incluindo os gestores escolares.

A mesma constatação é registrada por Reis (2011) que escreve que o mentor ou supervisor tem de constituir modelo na orientação da supervisão pedagógica. Para tal, é importante uma boa selecção de um profissional de qualidade que acumule simultaneamente competências técnicas e 
A supervisão pedagógica e a formação contínua: mitos e percepções por meio de narrativas...

pessoais. O Supervisor pedagógico, para além de ser formador, é um aprendiz, devido ao seu espírito paciente em ouvir o supervisionado.

O supervisor pedagógico, sendo um elemento chave, essencial na melhoria das práticas educativas, solicita-se uma série de requisitos, dentre elas a formação profissional, um certo nível de escolaridade ajustado à sua carreira. Segundo Waite (1995, 1999 apud MOREIRA, 2000), esses requisitos permitem a realização de uma supervisão que valoriza o diálogo e a participação dos principais actores, promovendo negociação, interacção, comunicação, realizações e autoavaliação entre os supervisores e seus supervisionados.

Entretanto, teoricamente, em Moçambique, não basta possuir o nível de escolaridade, o qualificador de carreiras profissionais do Ministério da Função Pública (MIFUPU) refere que, por exemplo, para ser instrutor técnico pedagógico de N1, a carreira que incorpora profissionais com qualificações para realizar supervisão em instituições de ensino secundário, na formação de professores e outras instituições educacionais, além da licenciatura em uma área das ciências da educação, deve possuir:

Três anos de experiência na carreira anterior; possuir, no mínimo, cinco anos de experiência docente; dominar o sistema e a metodologia de análise e planificação do processo de concepção, administração, direcção, metodologia e avaliação do SNE, bem como a legislação e regulamentação principal da actividade educativa; conhecer a política nacional educativa e a sua fundamentação filosófica e pedagógica; ter boa informação de serviço; ser aprovado em avaliação curricular, seguida de entrevista profissional para promoção. (MIFUPU, 2010, p. 321-325).

Desse modo, não existe recrutamento ou selecção na função pública para a função de supervisor pedagógico. A lei não define essa categoria profissional. Assim sendo, subentende-se que a supervisão é uma das várias tarefas atribuídas aos professores, que trabalham nas instituições de gestão de educação, desde os serviços distritais aos serviços centrais, assim como nos institutos de formação de professores. A supervisão pedagógica em Moçambique, de acordo com o qualificador das profissões, é uma atribuição e não uma carreira profissional.

Corroborámos com Alves (2008) que considera a supervisão pedagógica como processo em que um professor, em princípio mais experiente e mais informado, orienta um outro professor no seu desenvolvimento humano e profissional. Nesse sentido, o supervisor é, então, o orientador pedagógico, o educador a quem compete ajudar outro professor ou gestor educacional a desenvolver-se e a aprender como adulto e profissional que é. Ademais, Tavares e Alarcão (2003) consideram que a acção do supervisor se perspectiva em dois níveis distintos, embora relacionados entre si: $1^{\circ}$ exerce uma influência directa sobre o desenvolvimento e a aprendizagem do professor; e $2^{\circ}$ exerce uma influência indirecta sobre o desenvolvimento e a aprendizagem dos alunos.

Partindo do pressuposto de que todas estas alterações se constituem como um desafio à escola e ao trabalho docente, que se pretende cada vez mais autónomo e responsável, torna-se imperativa uma cultura de autoquestionamento, de autoavaliação, e de autossupervisão, como condições necessárias para encontrar dinamismo do trabalho que se desenvolve no dia a dia. Essas atitudes abrem espaço para que as práticas docentes sejam analisadas, avaliadas e reestruturadas de forma fundamentada (PARENTE, 2009 apud ALVES, 2013).

A reflexão deveria acontecer de forma regular e seriam os professores a pensar sobre os modelos educativos, não esquecendo a qualidade das aprendizagens, quer dos alunos, quer deles próprios no processo de formação permanente. Esse modo de perspectivar a escola exige uma nova organização e condições de trabalho, que permitam, entre outras, uma distribuição específica

Práxis Educativa, Ponta Grossa, v. 16, e2116810, p. 1-17, 2021

Disponível em: < https://www.revistas2.uepg.br/index.php/praxiseducativa> 
das tarefas aos técnicos (supervisores) para que saibam o que irão ou devem fazer ao chegar na escola por exemplo.

Moçambique, de um lado, enfrenta os desafios de se enquadrar nos avanços tecnológicos impostos pela sociedade global, altos níveis de escolarização e/ou formação dos professores; e, por outro lado, registra constantemente questionamentos em volta da qualidade de ensino e dos próprios professores. Nesse sentido, impõe-se que o supervisor não seja encarado apenas como um funcionário, um técnico ou mesmo um modelo, mas antes como um profissional competente e com um perfil altamente sugestivo.

Sacristán (2000) refere que a competência não é tanto uma técnica composta por uma série de destrezas baseadas em conhecimentos concretos ou na experiência, não se trata, portanto, de uma simples descoberta pessoal. Assim, o supervisor não pode ser um simples técnico, nem um improvisador, mas um profissional que pode utilizar o seu conhecimento e a sua experiência para ajudar a melhorar os contextos pedagógicos práticos de acordo com a realidade da escola.

Não basta dominar a didáctica da disciplina, a pedagogia ou ter muitos conhecimentos científicos para se considerar apto ou elegível ao cargo de supervisor, exige-se a experiência profissional pois o saber educativo inclui e é feito de todos esses elementos (ROLDÃO 2000). Em uma abordagem sistematizada, o autor refere que o saber profissional de qualquer área consiste antes na mobilização complexa, organizada e congruente, de todos esses saberes antes elencados em torno de cada situação concreta, no sentido da conquista do propósito determinante da acção profissional - no caso vertente o sucesso educacional.

\section{Metodologia da pesquisa}

Trata-se de um estudo qualitativo na variante narrativa. A adopção da metodologia narrativa na pesquisa em educação, embora menos consensual, é uma questão de se assumir, em uma perspectiva epistemológica das nossas práticas como identidade cultural e científica. Nesse sentido, como faz menção Freire (1996, p. 46-47), é “[...] assumir-se como ser social, e histórico, como ser pensante, comunicante, transformador, criador, realizador de sonhos, [...] assumir-se como sujeito porque capaz de reconhecer-se como objecto. A assunção de nós mesmos, não significa a exclusão dos outros".

A metodologia narrativa, nesta pesquisa, torna-se mais viável, pois exige atenção especial no processo de recolha de dados que deve acontecer por meio de diálogo com os sujeitos envolvidos. Para tal, o registo, a transcrição e a interpretação do que for revelado carece uma demonstração de modo a tornar acessível a sua partilha em contextos e fóruns de debate educacionais, sobretudo os vinculados à formação de professores.

Narração é melhor para que se aprenda com as aprendizagens dos outros, acumulados ao longo do tempo. É um desafio na contemporaneidade escolher narrativas para produzir conhecimento, em um tempo em que as tecnologias de informação e comunicação, a nova dinâmica social e os modos de produção não dispõem de tempo para que as pessoas conversem, o tempo solicita resultados de trabalho.

Sampaio, Arocena e Ribeiro (2018) levantam uma questão problemática para chamarem atenção sobre a necessidade de reaver algumas práticas em extinção. Não pode valer a pena procurar e/ou recorrer a essas outras formas de produzir conhecimento? E por que se assume a necessidade de questionamento científico? Essas inquietudes reforçam a convicção de adoptar outras formas de recolher dados sem ficar preso às "maquetes" da chamada ciência normal. 
Portanto, no trabalho empírico, recorremos aos textos de campo. Ao longo do trabalho, fomos registrando as constatações baseadas no que os textos diziam ou não diziam, a partir das nossas traduções ou anotações, conforme defende Souza (2017). Nesses textos (narrativas sobre experiências na supervisão), aconteciam paragens assombrosas, buscando subsídio em Benjamim (2014), ser um exercício mental de rupturas e conexões. Essas rupturas podem ser superadas a partir das traduções fiéis. Nesse caso, podemos não ter sido criativos como devíamos, mas esforçamo-nos a trazer a realidade expressa e omissa em volta da supervisão.

O estudo envolveu quatro professores que trabalham na Vila-Sede do Distrito de Monapo, na Província de Nampula, Norte de Moçambique, cujo critério de inclusão na pesquisa foi ter trabalhado como técnico no Serviço Distrital de Educação, Juventude e Tecnologia, ou ter sido Coordenador da Zona de Influência Pedagógica, instituições responsáveis pela excussão do processo de supervisão escolar. Para além do perfil ora referenciado, os participantes do estudo são professores cujo tempo de serviço na educação variava entre 17 e 36 anos. Assim, dois dos participantes atingiram o tempo de reforma estabelecido no Estatuto Geral dos Funcionários e Agentes do Estado ${ }^{5}$. No que tange ao nível acadêmico, três dos participantes são licenciados, e um tem nível médio. Importa salientarmos que ambos passaram por uma formação psicopedagógica inicial, com duração de dois anos.

\section{Procedimentoss éticos}

A realização da pesquisa foi mediante a apresentação de uma credencial fornecida pela Universidade Católica de Moçambique - Faculdade de Educação e Comunicação na ZIP de Monapo-Sede, tendo em seguida identificado os professores (participantes) da pesquisa. Importa salientarmos que a participação dos professores foi voluntária e livre, com base na assinatura de uma declaração de consentimento informado. Concordamos em não publicar a identidade dos professores, razão que nos levou a codificar as fontes dos textos produzidos pelos participantes em números naturais, ex.: Professor 1; Professor 2, e assim sucessivamente. Temos a sublinhar que não houve troca de favores nem ofertas monetárias aos participantes. $O$ único incentivo foi a explicação que demos aos participantes sobre a importância do estudo para os pesquisadores e aos próprios participantes enquanto professores de carreira.

\section{Resultados}

Apresentamos os resultados deste estudo em duas categorias, nomeadamente: a) o papel do supervisor pedagógico na escola; e b) percep̧ões/mitos sobre a supervisão pedagógica na escola. A sua definição foi mediante a tendência e afinidade das respostas. Durante a recolha de dados, os participantes, por meio de textos, referiram haver uma complexidade na efectivação do processo de supervisão pedagógica na escola. Assim, os resultados demostram haver amplitudes (prós e contras) dos vários estilos de supervisão exercidos nas escolas.

\section{a) O papel do supervisor pedagógico na escola}

$\mathrm{Da}$ análise que fizemos a volta dos textos apresentados pelos participantes da pesquisa, constatamos haver uma interpretação errónea sobre as responsabilidades atribuídas aos supervisores que se deslocam das instituições gestoras de educação (Serviço Distrital de Educação,

\footnotetext{
5 O Artigo 154 do Estatuto Geral dos Funcionários e Agentes do Estado da República de Moçambique, aprovado pela Lei No 10/2017, de 1 de agosto, estabelece 35 anos de serviço e 60 ou 55 anos de idade consoante o sexo masculino ou feminino, respectivamente (REPÚBLICA DE MOÇAMBIQUE, 2017).
} 
Juventude e Tecnologia, assim como da Direcção Provincial de Educação e Desenvolvimento Humano) às escolas. Desse modo, na óptica dos participantes, os supervisores transformam a sua actividade em um momento de exercício do poder autoritário, conforme o trecho a seguir:

Recordo-me de um episódio que aconteceu em Março de 2009, quando trabalhava na Escola Primária de Naquite, no Distrito de Monapo. Um dia, no âmbito da supervisão pedagógica, chegou à escola um técnico do Serviço Distrital de Educação Juventude e Tecnologia por volta das 9 horas, assistiu à minha aula e, por fim, disse-me que não reunia condições para ser professor. Como consequência disso, enviaria um relatório para a escola explicando todas as imperfeiçoes que cometi, por um lado, e sugeria à Direçãa Distrital para Rescindir o meu contrato. (Texto do Professor 1).

O outro texto revela uma história vivida de perto, ou seja, o narrador refere que grande parte dos supervisores não conhecem as suas atribuições, para além de não possuírem experiência suficiente para o exercício da actividade de supervisão, o que denota a não observância aos critérios definidos no perfil do técnico pedagógico, conforme o extrato que segue:

\begin{abstract}
Não aconteceu comigo, mas vi e senti de perto. Em 2013, estávamos em plenas provas provinciais ${ }^{6}$, aparece um técnico naquela escola a fim de trabalhar, numa altura em que deccoria a prova de Filosofia e, de repente, um estudante foi encontrando com uma cábula por um professor da escola e, de seguida, este anunciou que aquilo era fraude académica. Porém, para o nosso espanto, o supervisor disse-nos que, por se tratar de provas provinciais, não cabia à direção da escola e muito menos ao professor que descobriu declarar fraude. Portanto, devia ser o técnico do serviço distrital a verificar as circunstâncias para depois declarar ou não a fraude académica. Quando fizemos busca de informacões, ficamos a saber que aquele técnico era recém-formado com o modelo de $10^{a}$ classe +1 ano, nunca tinha dado aula em nenhuma escola e estava colocado no Serviço Distrital a menos de um ano. (Texto do Professor 4).
\end{abstract}

\title{
b) Percepções/mitos sobre a supervisão pedagógica na escola
}

Como registramos na categoria anterior, a supervisão pedagógica tem constituído uma fonte de discórdias entre os supervisores de diferentes níveis e os professores em todos os subsistemas de ensino. Nessa categoria, os resultados revelam uma tendência bifocal sobre a supervisão enquanto uma actividade rotineira do processo educativo. As transcrições de textos que apresentamos a seguir demonstram essa realidade:

Os professores encaram a supervisão pedagógica com horror, falo isso por vários episódios que vivi durante estes 26 anos que trabalho como professor. Um dos episódios foi em 2017, quando trabalhava na Escola Primária Completa de Napala, No Distrito de Monapo, recebemos uma técnica vinda dos Serviços Distritais de Educação, Juventude e Tecnologia de Monapo. Diferentemente do que os outros fazem, ela apresentou-se e mostrou os termos de referência. Um dos objectivos era assistência às aulas da $2^{a}$ classe. A substituta do Adjunto Pedagógico indicon a professora, que deveria ser assistida. Quando foi comunicada, disse que naquele dia não queria ser assistida leccionando. Mas como a Direção estava ciente de que tal professora enfrentava várias dificuldades na administração do Processo de Ensino-Aprendizagem, houve insistência por parte da direcção em ser assistida à aula da mesma professora pela supervisão [...]. Consumada a assistência à aula, seguiu-se ao momento de interacção tripartida (professora, direç̧ão da escola e a técnica-supervisora). Foi dada a palavra à professora, a fim de fazer uma a autoavaliação, disse que não estava preparada para ser assistida. Por seu turno, a supervisora, para além de ter falado da falta de capacidade de controlar a turma por parte da professora, deixou algumas recomendaçoes para a melhoria dos aspectos negativos que considerou serem extremamente urgentes para fazer face à aprendizagem das crianças. Numa outra ocasião, a supervisora regressou à escola para a segunda ronda de assistência às aulas e pediu que voltasse a assistir às aulas da mesma professora que, noutrora, havia assistido. Todavia, a professora fez. uma grande guerra, bateu no pé, dizendo que jamais permitiria que a mesma técnica entrasse, pela segunda vez, em sua turma, dado que já lhe havia assistida na primeira ronda. Mais uma vez, precison da intervenção da direçãa da escola para que a professora permitisse a entrada da supervisora. A propósito, houve um ambiente de descrença e de desânimo até de ódio por parte da professora, que alegou ser uma perseguição. (Texto do Professor 3).

O outro cenário de fobia mórbida desenvolvida pelos professores em torno da supervisão pedagógica é descrito por um professor que trabalhou por longos anos como técnico pedagógico

\footnotetext{
${ }^{6}$ São avaliações sumativas em que os estudantes do Ensino Secundário são submetidos ao final de cada semestre.

7 São textos em miniatura que, geralmente, os estudantes produzem nas vésperas das avaliações resumindo os conteúdos abordados ao longo do trimestre ou ano, para uso fraudulento.
}

Práxis Educativa, Ponta Grossa, v. 16, e2116810, p. 1-17, 2021 Disponível em: < https://www.revistas2.uepg.br/index.php/praxiseducativa> 
A supervisão pedagógica e a formação contínua: mitos e percepções por meio de narrativas...

na Direcção Distrital de Educação, que também trabalhou como professor e agora está aposentado. No seu texto breve, ele descreve um episódio que vivenciou em uma das Escolas do Posto Administrativo de Itoculo, como transcrevemos a seguir:

Era de manhã, por volta das 8:00H, quando chegamos à Escola Primária 3 de Fevereiro, encontramos a direcção da escola no recinto e os professores em sala de aula. Depois de um breve encontro com a direcção, pedimos para assistir às aulas, um dos professores indicados disse que estava a administrar um teste. Não nos incomodamos, explicamos que a avaliação também é uma aula, precisa ser planificada e estávamos dispostos a assisti-lo. Ai, o professor entrou pela porta da sala, saltou pela janela e jamais regressou para a escola naquela manhã de Maio de 2009. (Texto do Professor 2).

Ao olharmos para os resultados que acabamos de transcrever, entendemos que a supervisão cria controvérsias tanto para os técnicos responsáveis pela sua realização, assim como e, sobretudo, nos professores supervisionados, desde o Ensino Pré-Escolar ao Ensino Superior. Portanto, embora legalmente a supervisão pedagógica constitua um processo formativo e de aperfeiçoamento profissional, a realidade mostra que ser supervisionado não passa de um julgamento; assim, a maior parte dos professores encaram-na como espaço de exercício do poder, subjugação ou ameaça do supervisor para com supervisionado. Esses resultados confirmam o contrário da finalidade de qualquer que seja o tipo de supervisão. Aliás, como referem Gaspar, Seabra e Neves (2012), a supervisão é uma actividade complexa, pois barca domínios como a administração, o ensino, a saúde escolar e "serviços". Portanto, "[...] as operações que realiza por excelências são observação, orientação e avaliação, podendo apresentar-se em três estruturas diferentes: a supervisão vertical, a supervisão horizontal e a auto supervisão" (GASPAR; SEABRA; NEVES, 2012, p. 30-31).

A indicação de pessoas menos experientes e sem qualificação profissional necessária para o exercício da tarefa de supervisionar abre espaço para tensão e resistência quase inevitável dos professores e contribui para a manutenção dos mitos construídos à volta da supervisão pedagógica. Teoricamente, a supervisão pedagógica é uma oportunidade de formação e aperfeiçoamento profissional do professor. Entretanto, a reprodução sugestiva e ameaçadora do modelo inspectivo da supervisão transmitido informalmente aos professores recém-formados cria esse ambiente de homofobias, que chegam a gerar ódio e violência nas instituições de ensino.

Partilhamos a mesma ideia com Reis (2011) que defende a necessidade da selecção de sujeitos competentes entre os professores para exercerem o papel de supervisor pedagógico. Para além das competências técnicas, precisa ser um indivíduo com elevadas qualidades de comunicação, que encoraja, aconselha os supervisionados, analisa, reflecte, ouve, programa acções, define objectivos, é acessível, mas discute os factos com o propósito de apoiar. Estamos cientes de que essas qualidades e competências não se adquirem de forma espontânea. Indicar um professor recém-graduado para exercer a tarefa de supervisor é um desperdício duplicado de recursos. Com esse exercício, a educação ganha um mau técnico supervisor ao mesmo tempo que lhe impede de vivenciar empiricamente situações didácticas problemáticas que podiam contribuir na sua formação por meio de interacção com os outros aquilo que Nóvoa (2017) chama de interposição pedagógica.

\section{Conclusão}

Que percepções os professores têm sobre a supervisão pedagógica? Foi a questão básica que norteou todo processo de investigação que envolveu professores do Distrito de Monapo, na Província de Nampula, Norte de Moçambique, por meio de narrativas expostas em textos de campo produzidos a partir da nossa solicitação durante o processo de recolha de dados. Assim, os resultados permitem-nos concluir que, embora haja um relativo esforço para a desconstrução dos mitos associados à supervisão pedagógica, ela continua a ser percebida como meio de coacção feita pelos professores e retaliação dos gestores escolares.

Práxis Educativa, Ponta Grossa, v. 16, e2116810, p. 1-17, 2021 Disponível em: < https://www.revistas2.uepg.br/index.php/praxiseducativa> 
Olhando pelas variantes da supervisão, que deve acontecer na variante vertical, horizontal e intrínseca (autossupervisão), concluímos que ela acontece de forma acidental e sempre na modalidade vertical. Por conseguinte, a supervisão da actividade educativa é exclusivamente reservada aos técnicos de nível distrital e/ou provincial e sempre emparelhada ao mito da punição que os supervisores carregam. Com efeito, a partir das nossas experiências profissionais, constatamos que a maioria dos professores em todos os subsistemas de ensino planificam e organizam suas aulas e recursos didácticos, quando tomam conhecimento da vinda de uma equipa de supervisão. Porquanto, a supervisão, se vista como uma prática punitiva, não contribui para o crescimento profissional dos professores. Pelo contrário, se for entendida como prática cooperativa, contribui para a melhoria das práticas docentes, com consequências nas aprendizagens dos alunos.

\section{Referências}

ALVES, A. I. D. M. A supervisão pedagógica: da interacção à construção de identidades profissionais - estudo de caso. Lisboa: Universidade Aberta, 2008.

ALVES, A. P. F. A supervisão pedagógica e a reflexividade docente. 2013. Dissertação (Mestrado em Supervisão Pedagógica) - Universidade da Beira Interior, Ciências Sociais e Humanas, Covilhã, 2013.

BARBOSA, A. G.; MAURIDE, F. A supervisão e a inspeção escolar no enquadramento legal da educação em Moçambique. In: BARBOSA, A. G. et al. (org.). Desafios da Educação: Leituras Actuais. Nampula: Década das Palavras, 2017. p. 145-163.

BARBOSA, A. G. et al. A percepção das competências profissionais nos professores do ensino superior. Revista de investigação em educação, comunicação e desenvolvimento: educação, desenvolvimento e cultura organizacional, Nampula, v. 1, n. 1, p. 115-128, 2016.

BENJAMIM, W. Magia e Técnica, Arte e Política: ensaios sobre a literatura e historiais da cultura. 8. ed. São Paulo: Editora Brasiliense, 2014.

BORGES, A. M. C. Reformas do Estado, emprego público e precarização do mercado de trabalho. Cadernos CRH, Salvador, v. 17, n. 41, p. 255-268, mar./ago. 2004. DOI: http://dx.doi.org/10.9771/ccrh.v17i41.18493

CHAMBEL, J. C.; CURRAL, L. Psicossociologia das organizações. Lisboa: Texto Editora, 1995.

COMITÉ DE CONSELHEIROS. Agenda 2025: visão e estratégia da Nação. Maputo: Editora Yoyoyoyo, 2003.

FREIRE, P. Pedagogia da autonomia: saberes necessários à prática educativa. São Paulo: Paz e Terra, 1996.

GASPAR, M. I.; SEABRA, F.; NEVES, C. A supervisão pedagógica: significados e operacionalização. Revista Portuguesa de Investigação Educacional, Lisboa, n. 12. p. 29-57, 2012. DOI: https://doi.org/10.34632/investigacaoeducacional.2012.3374

GOLIAS, M. E. Sistema de ensino em Moçambique, passado e presente. Maputo: Editora Escolar, 1993. 
INSTITUTO NACIONAL DE ESTATÍSTICA; MINISTÉRIO DA SAÚDE. Inquérito Demográfico de Saúde. Maputo: MISAU e ORC Macro de Moçambique 2011.

LARROSA, J. Tremores: escritos sobre experiência. Tradução Cristina Antunes, Jorge Larrosa e João Wanderley Geraldi. Colecção Educação: Experiência e Sentido. São Paulo: Editora Autêntica, 2014.

LIBÂNEO, J. C. Didáctica Geral. São Paulo: Editora Cortez, 1994.

LIBARDI, D. A. O papel do professor universitário na construção do conhecimento. Revista de Educação, Londrina, v. 15, n. 15, p. 9-26, 2010.

LOPES, J. S. M. A Pós-Graduação, a formação docente e a qualidade no Ensino Superior. In: ENCONTRO NACIONAL DE PESQUISA EM EDUCAÇÃO, 1., 2017, Maputo. Proceedings [...]. Maputo: Universidade Eduardo Mondlane, 2017.

MEDEIROS, E. A.; FORTUNATO, I.; ARAÚJO, O. H. A. Professores orientadores dos estágios supervisionados das licenciaturas do Brasil: análise de teses nacionais 2014-2018. Revista Práxis Educacional, Vitória da Conquista, v. 16, n. 43, p. 29-50, dez. 2020. DOI: https://doi.org/10.22481/praxisedu.v16i43.6777

MIFUPU. Ministério da Função Pública. Centro Nacional de Documentação e Informação de Moçambique (CEDIMO). Qualificador profissional de carreiras, categorias e funções de direcção, chefia e confiança em vigor no aparelho do Estado. Maputo: Livraria Escolar Editora, 2010.

MOREIRA, M. Para a inovação das práticas supervisivas: um programa de formação de supervisores pela investigação-acção. In: ROLDÃO, M. C; MARQUES, R. (org.). Inovação, currículo e formação. Porto: Porto Editora, 2000. p. 137-149.

NACUO, P. Boroma: uma homenagem a todos os professores. Maputo: Notícias, 2008.

NASCIMENTO, L. C. Um diploma em disputa: a obrigatoriedade do diploma em jornalismo no Brasil. Sociedade e Cultura, Goiânia, v. 14, n. 1, p. 141-150, jan./jun. 2011. DOI: https://doi.org/10.5216/sec.v14i1.15688

NÓVOA, A. Desafios do Trabalho e formação docente no Século XXI. Palestra com os professores do Sindicato dos Professores de Nova Hamburgo, 2017. Disponível em: https://www.youtube.com/watch?v=sYizAm-j1rM. Acesso em: 12 jan. 2020.

PERRENOUD, P.; THURLER, M. G. As competências para ensinar no século XXI: a formação dos professores e os desafios da avaliação. São Paulo: Artmed, 2008.

REIS, P. Observação de aulas e avaliação do desempenho docente. Lisboa: Editora Ministério de Educação; Conselho Científico para Avaliação de Professores, 2011.

REPÚBLICA DE MOÇAMBIQUE. Lei No 10, de 1 de agosto de 2017. Aprova o Estatuto Geral dos Funcionários e Agentes do Estado. Boletim da República: Suplemento I Serie n. 119. Maputo, 2017.

REPÚBLICA DE MOÇAMBIQUE. Lei N ${ }^{\text {o. }}$ 18, de 28 de dezembro de 2018. Estabelece o novo quadro jurídico legal do Sistema Nacional da Educação em Moçambique. Boletim da República: I Série. $2^{\circ}$ Suplemento. Maputo. 2018. 
REPÚBLICA DE MOÇAMBIQUE. Assembleia Popular de Moçambique. Lei No 4, de 23 de março de 1983. Lei do Sistema Nacional de Educação. Boletim da República: I Série. $2^{\circ}$ Suplemento. Maputo. 1983.

REPÚBLICA DE MOÇAMBIQUE. Ministério de Educação e Cultura. Diploma Ministerial No 76, de 11 de setembro de 1978. Instituiu a Inspecção-Geral da Educação e Cultura. Boletim da República: $2^{\mathrm{a}}$ série. 1978.

ROLDÃO, M. C. A problemática da diferenciação curricular o contexto das políticas educativas atuais. In: ROLDÃO, M. C; MARQUES, R. (org.). Inovação, currículo e formação. Porto: Porto Editora, 2000. p. 121-133.

SACRISTÁN. J. G. O currículo: uma reflexão sobre a prática. 3. ed. São Paulo: Artmed Editorial, 2000.

SAPATO, P. R. Os desafios da educação na atualidade. Revista de investigação em educação, comunicação e desenvolvimento: educação, desenvolvimento e cultura organizacional, Moçambique, v. I, n. 1, p. 11-21, 2016.

SAMPAIO, C. S.; AROCENA, M.; RIBEIRO, T. Prefácio. In: RIBEIRO, T.; SOUSA, R.; SAMPAIO, C. S. (org.). Conversa como metodologia de pesquisa: por que não? Rio de Janeiro, Ayu, 2018. p. 7-8.

SAPATO, P. R. Os desafios da educação na atualidade. Revista de investigação em educação, comunicação e desenvolvimento: educação, desenvolvimento e cultura organizacional, Moçambique, v. I, n. 1, p. 11-21, 2016.

SOUZA, E. C. Experiências e narrativas: redes de pesquisa - ação - formação. In: PÉREZ, C. L. V. (org.). Experiências e narrativas em Educação. Niterói: Universidade Federal Fluminense, 2017. p. 9-14.

TAVARES, C. F. Novas competências para ensinar, mais caminhos a percorrer: um percurso. Porto. In: ROLDÃO, M. C.; MARQUES, R. (org.). Inovação, currículo e formaçãa. Porto: Porto Editora, 2000. p. 225-245.

TAVARES, J.; ALARCÃO, I. Psicologia de desenvolvimento e da aprendizagem. Coimbra: Editora Livraria Almedina, 2003.

Recebido em 13/010/2020

Versão corrigida recebida em 20/12/2020

Aceito em 28/12/2020

Publicado online em 13/01/2021

Práxis Educativa, Ponta Grossa, v. 16, e2116810, p. 1-17, 2021

Disponível em: <https://www.revistas2.uepg.br/index.php/praxiseducativa $>$ 